\title{
Rasgos estilizados de la relación entre inversión y crecimiento en América Latina, 1980-2012
}

\author{
Sandra Manuelito y Luis Felipe Jiménez
}

RESUMEN

Mediante estimaciones de la inversión y sus componentes en América Latina en los últimos 30 años, se revisan hechos estilizados de su evolución y se exploran factores que explican su relación con el crecimiento económico. Se destaca el bajo nivel de inversión, la reducción de la inversión pública en los años ochenta y su parcial recuperación junto con la inversión privada entre 2003 y 2010. Se constata la influencia que tuvo el aumento del ingreso nacional debido a la mejoría de los términos de intercambio. Ello posibilitó el incremento del ahorro nacional y de su contribución al financiamiento de la inversión entre 2004 y 2008. El análisis de causalidad entre el coeficiente de inversión y el crecimiento del producto interno bruto (PIB), sugiere que - para un número relevante de países latinoamericanos - cambios en la tasa de crecimiento han precedido a cambios en el coeficiente de inversión en el período estudiado.

PALABRAS CLAVE

CLASIFICACIÓN JEL

AUTORES
Inversiones, inversión pública, capital, formación de capital, ingreso nacional, ahorros, crecimiento económico, América Latina

$\mathrm{E} 01, \mathrm{E} 21, \mathrm{E} 22$

Sandra Manuelito es oficial de asuntos económicos de la División de Desarrollo Económico de la Comisión Económica para América Latina y el Caribe (CEPAL). sandra.manuelito@cepal.org

Luis Felipe Jiménez es experto de la División de Desarrollo Económico de la Comisión Económica para América Latina y el Caribe (CEPAL).1fjimenez1953@gmail.com 


\section{I}

\section{Introducción}

Una de las dificultades que enfrenta el análisis del crecimiento y el desempeño macroeconómico de América Latina, ha sido la insuficiente información estadística relacionada con la evolución de algunas variables que son compiladas en el marco de las cuentas nacionales de los países. Sobre todo se requiere una mayor desagregación de los niveles de inversión, en términos de su composición según agente institucional y sectores de destino de la inversión, así como lo relacionado con el financiamiento de la inversión, esto es, el ahorro y sus componentes. El propósito de este artículo es contribuir a llenar algunos de estos vacíos estadísticos, y a la vez dar cuenta de los principales rasgos estilizados de la inversión y el ahorro durante el período 1980-2012. Además, sobre la base de la información estadística compilada, se explora empíricamente la relación entre inversión y crecimiento.

Tomando como referencia las estadísticas oficiales de las cuentas nacionales de los países de la región, se elaboraron estimaciones de la formación bruta de capital fijo (FBCF) y de sus componentes, tanto según sector institucional (inversión pública y privada), como por el tipo de inversión (inversión en construcción y maquinaria y equipo). Para estos efectos se reunió y sistematizó información de frecuencia anual proveniente de cuentas nacionales, reportada por los institutos de estadística o los bancos centrales de los países latinoamericanos, conjuntos estadísticos compilados y publicados por la Comisión Económica para América Latina y el Caribe (CEPAL), y datos disponibles en distintas fuentes (anuarios estadísticos nacionales, informes ministeriales, boletines estadísticos nacionales) y formatos (archivos electrónicos y documentos impresos), pero que no estaba agrupada

$\square$ Los autores agradecen los comentarios de Manuel Marfán, Juan Alberto Fuentes, Luis Felipe Céspedes, Osvaldo Kacef y Luis Eduardo Escobar a versiones preliminares del texto, así como la colaboración de Michael Seitz en lo referente al tratamiento de la información estadística; también agradecen los comentarios de dos árbitros anónimos. y sistematizada. En los casos en que no se dispuso de información estadística, ello se hizo respecto de aquellos años en que fue posible hacer interpolaciones, sea de tasas de crecimiento o de ratios. Cuando lo anterior no fue posible, no se obtuvieron datos. En todos los demás casos, la metodología asegura la consistencia y coherencia de las series de datos de inversión estimadas con la información oficial de las cuentas nacionales publicada por los países.

Del mismo modo, se realizaron estimaciones para las series de ahorro total, tanto del externo como del nacional, este último desagregado en su componente público y privado. La limitada disponibilidad de cuentas institucionales elaboradas y publicadas por los países no permitió avanzar hacia una estimación regional del ahorro en términos del ahorro del sector privado no financiero y del de los hogares.

Las series estadísticas correspondientes a estas estimaciones están disponibles para consulta ${ }^{1}$. Su posible uso es bastante amplio tanto en análisis teóricos como aplicados, y resulta muy relevante para el análisis de la evolución de la inversión en el período 1980-2010 en América Latina.

El artículo se desarrolla de la siguiente manera. Luego de esta Introducción, en la sección II se abordan, para el período comprendido entre 1980 y 2012, los principales hechos estilizados de la inversión, su evolución y los factores que incidieron en su aumento. Finalmente, en la sección III, se ofrece una síntesis y se presentan las conclusiones más relevantes.

\footnotetext{
${ }^{1}$ Las series estadísticas utilizadas en este estudio corresponden a una versión actualizada de las series estadísticas publicadas en Manuelito y Jiménez (2013), y están disponibles en formato electrónico previa solicitud a los autores. Se debe tener presente que, si bien se hizo el esfuerzo necesario para asegurar la compatibilidad de estas series con la información estadística oficial publicada por los países, así como con otras publicaciones de la CEPAL, estas estimaciones no corresponden a datos oficiales de los países, por lo que al citar la fuente de información esta debe remitirse al presente artículo.
} 


\section{II}

\section{Principales hechos estilizados de la inversión durante el período 1980-2012}

\section{Evolución de la inversión en ese período}

En comparación con países emergentes que han logrado elevadas tasas de crecimiento del PIB en forma sostenida, la tasa de inversión en los países de América Latina es por lo general baja. Tomando el año 1980 como punto de partida, la FBCF medida como porcentaje del PIB cayó en forma sostenida durante el primer lustro de los años ochenta y se mantuvo en una cifra inferior al $20 \%$ hasta 2007, para llegar a su cota más baja en 2003 (16,7\%). Desde entonces hasta 2012, la tasa de inversión mantuvo un crecimiento sostenido, alcanzando el $22,9 \%$ en este último año. No obstante, este valor es todavía inferior a los registros de 1980 y 1981 (véase el gráfico 1) ${ }^{2}$.

${ }^{2}$ Siguiendo la práctica de la compilación de estadísticas de inversión, esta y sus componentes se presentan empleando cálculos a precios constantes. En contraste, las estadísticas relacionadas con el financiamiento de la inversión, esto es del ahorro total, se presentan a precios corrientes. Ello se debe, por una parte, a que con las series estadísticas que sirven de base a los análisis presentados en este artículo se procura mantener la consistencia con las estadísticas publicadas por los países. Por otra, definir un deflactor para el ahorro presenta dificultades metodológicas sobre las cuales no existe consenso técnico, ni en lo relacionado con el deflactor apropiado ni con la interpretación económica de ese
Tales resultados contrastan con los de economías emergentes asiáticas que han registrado altas tasas de crecimiento en las décadas recientes. En el gráfico 2 se presenta la evolución comparada de la tasa de inversión en esas economías y las de la región. Entre las economías asiáticas destacan China y la India con elevadas tasas

\begin{abstract}
deflactor. En el presente artículo se tomaron como referencia las series en moneda nacional a precios constantes publicadas por los países incluidos en el estudio, manteniendo las respectivas bases de cuentas nacionales, dado que el interés de este trabajo fue compilar series relativamente largas de coeficientes de inversión como porcentaje del PIB. Haber hecho un ejercicio de retropolación de las series en valor absoluto, de manera de expresar estos niveles en una misma base y posteriormente calcular el coeficiente de inversión, hubiera generado coeficientes de inversión distintos de los publicados por los países de acuerdo con sus cifras oficiales. Además, en esta oportunidad no se recopilaron ni estimaron series de formación bruta de capital fijo (FBCF) a precios corrientes a causa de la muy limitada disponibilidad de información estadística. Pocos países de la región compilan este agregado de cuentas nacionales, y los datos disponibles se hacen más escasos a medida que se pretende construir series más largas. A esto se suman elementos metodológicos, tales como los precios implícitos en la estimación de la formación bruta a precios corrientes que, en el caso del período bajo análisis en el presente artículo (1980-2012), generan dificultades para el análisis económico, en particular, debido a los casos de elevada inflación registrados a finales de los años ochenta e inicios de la década de 1990.
\end{abstract}

GRÁFICO 1

América Latina: formación bruta de capital fijo como porcentaje del PIB, 1980-2012 (En dólares constantes de 2005)

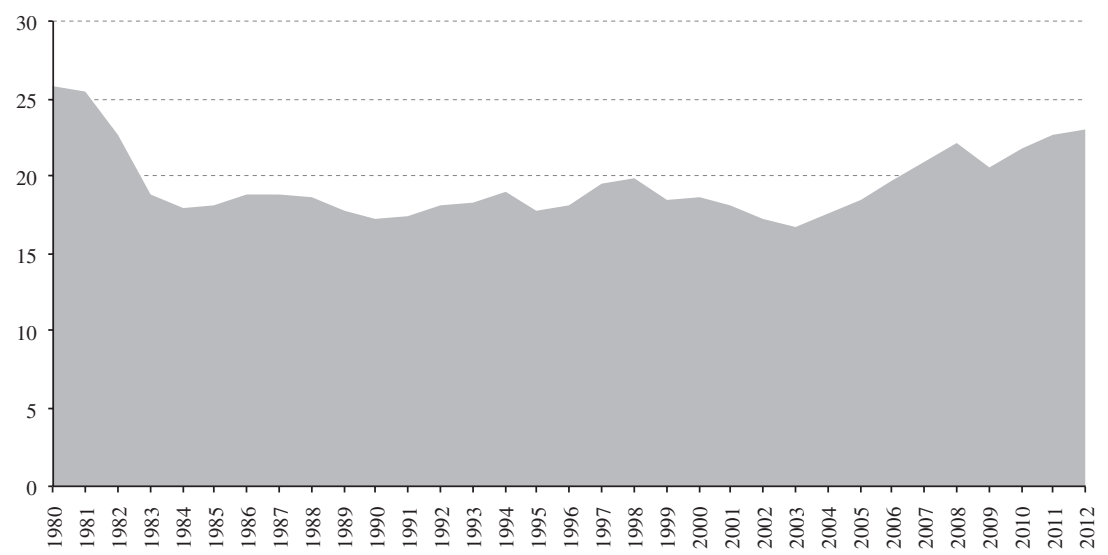

Fuente: elaboración propia sobre la base de Comisión Económica para América Latina y el Caribe (CEPAL), "América Latina y el Caribe: Series históricas de estadísticas económicas 1950-2008”, Cuadernos Estadísticos, No 37 (LC/G.2415-P), Santiago de Chile, 2009. PIB: producto interno bruto. 
(En moneda nacional a precios constantes y dólares constantes de 2005)

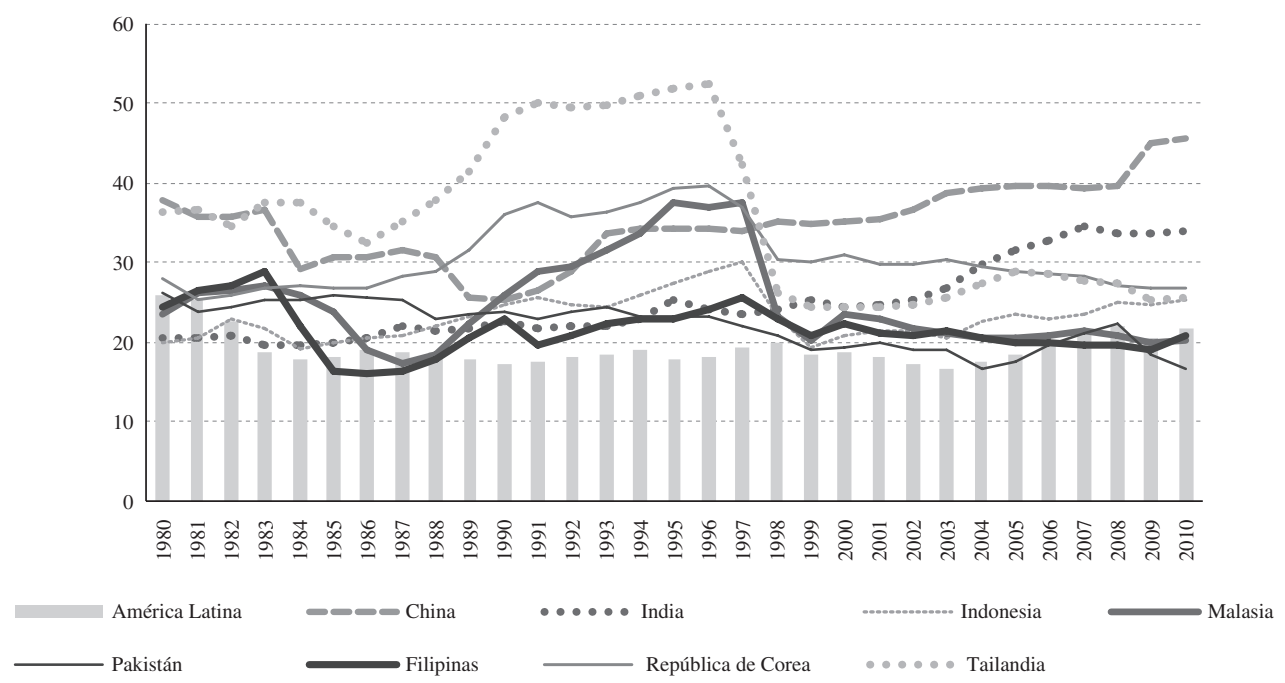

Fuente: elaboración propia sobre la base de Comisión Económica para América Latina y el Caribe (CEPAL), "América Latina y el Caribe: Series históricas de estadísticas económicas 1950-2008”, Cuadernos Estadísticos, No 37 (LC/G.2415-P), Santiago de Chile, 2009 y Naciones Unidas, datos de UNdata.

PIB: producto interno bruto.

de inversión, en torno del $45 \%$ del PIB y $35 \%$ del PIB, respectivamente, seguidas por la República de Corea y Tailandia, con niveles cercanos a un $25 \%$ del PIB. Salvo en los últimos años, la tasa de inversión de América Latina se sitúa sistemáticamente por debajo de los niveles anotados en estos países.

En los cuadros 1, 2 y 3 se presenta el promedio de las tasas de inversión ${ }^{3}$ de 19 países de América Latina para los que se dispone de información estadística respecto del período 1980-2010, desagregada por sector institucional (inversión pública y privada), así como por tipo de inversión (inversión en construcción y en maquinaria y equipo). Los datos se presentan de acuerdo con subperíodos específicos, definidos según los rasgos de la evolución de la actividad económica regional. El primer subperíodo abarca desde 1980 a 1989 y corresponde a los años de la crisis de la deuda externa en América Latina. El segundo subperíodo comprende de 1990 a 1998, años en que se registró un crecimiento económico generalizado y sostenido, salvo en los casos de la Argentina y México, ambos afectados por la crisis de balanza de pagos en este último país entre 1994-1995.

\footnotetext{
${ }^{3}$ Referido a la formación bruta de capital fijo como porcentaje del $\mathrm{PIB}$, en moneda nacional a precios constantes.
}

El tercer subperíodo corresponde a 1999-2002, durante el cual se observó un bajo crecimiento en muchas de las economías de la región debido a las consecuencias de la crisis asiática, a los shocks financieros en algunos países latinoamericanos y a la desaceleración económica en los Estados Unidos de América durante 2000-2001. Finalmente, el cuarto subperíodo incluye los años comprendidos entre 2003 y 2010, que corresponden a los años recientes de crecimiento de las economías latinoamericanas. Si bien este dinamismo se vio interrumpido en 2009 a consecuencia de los efectos de la crisis financiera global, la región registró en promedio en 2010 tasas de crecimiento similares a las observadas entre 2003 y 2008, inclusive.

Del análisis de los resultados de los cuadros 1 y 2 se desprenden tres hechos estilizados. En primer término, en 8 de los 19 países considerados (Argentina, Bolivia (Estado Plurinacional de), Brasil, Cuba, El Salvador, Guatemala, Paraguay y Uruguay) la FBCF como porcentaje del PIB se mantuvo en forma prolongada en niveles inferiores al 20\%. En segundo lugar, en comparación con la década de 1980, en el subperíodo 1990-1998 la inversión pública medida como porcentaje del PIB disminuyó en 15 de los 19 países, lo que en algunos casos se extendió hasta el subperíodo 1999-2002. A partir del año 2003 se aprecia una recuperación de este 
América Latina: formación bruta de capital fijo como porcentaje del PIB, 1980-2010a (En moneda nacional a precios constantes)

\begin{tabular}{|c|c|c|c|c|}
\hline País & 1980-1989 & $1990-1998$ & 1999-2002 & $2003-2010$ \\
\hline Argentina & 19,3 & 18,4 & 16,0 & 20,3 \\
\hline Bolivia (Estado Plurinacional de) & 12,1 & 16,0 & 16,6 & 14,8 \\
\hline Brasil & 18,5 & 18,1 & 15,9 & 17,3 \\
\hline Chile & 17,6 & 26,4 & 23,0 & 24,7 \\
\hline Colombia & 16,6 & 20,0 & 13,7 & 21,5 \\
\hline Costa Rica & 19,7 & 20,9 & 20,9 & 21,8 \\
\hline Cuba & 25,5 & 14,8 & 11,8 & 11,5 \\
\hline El Salvador & 12,5 & 17,8 & 19,2 & 18,1 \\
\hline Guatemala & 9,7 & 10,4 & 15,6 & 17,3 \\
\hline Honduras & 16,7 & 21,8 & 24,9 & 24,8 \\
\hline México & 18,9 & 17,9 & 20,0 & 21,1 \\
\hline Nicaragua & 18,4 & 18,6 & 25,3 & 21,7 \\
\hline Panamá & 18,2 & 20,9 & 18,5 & 20,9 \\
\hline Paraguay & 21,9 & 22,9 & 16,6 & 17,9 \\
\hline Perú & 20,5 & 20,6 & 19,0 & 22,5 \\
\hline Uruguay & 12,7 & 14,5 & 13,0 & 16,8 \\
\hline Venezuela (República Bolivariana de) & 20,9 & 17,7 & 24,4 & 27,3 \\
\hline América Latina ${ }^{b}$ & 17,7 & 19,0 & 19,0 & 20,4 \\
\hline
\end{tabular}

Fuente: Comisión Económica para América Latina y el Caribe (CEPAL), Anuario Estadístico de América Latina y el Caribe, varios años.

a En los cuadros 1 a 7 se emplean promedios simples para calcular la tasa de inversión regional en términos agregados. Considerar a todos los países con igual ponderación dentro del agregado regional permite compararlos entre sí, independientemente del tamaño de su economía y facilita la comparación entre la experiencia de un país vis à vis un caso representativo de la región. Si se empleara un promedio ponderado, el caso típico regional pasaría a estar dominado por los tres países de mayor tamaño. De hecho, ambas prácticas se ocupan en los documentos de la CEPAL, dependiendo de si se está dando cuenta del desempeño de la región en su totalidad (caso en que se emplean promedios ponderados) o se están abordando temas de política (caso en que se emplean promedios simples de países).

b Corresponde al promedio simple de los países considerados.

PIB: producto interno bruto.

CUADRO 2

América Latina: formación bruta de capital fijo pública y privada como porcentaje del PIB, 1980-2010

(En moneda nacional a precios constantes)

\begin{tabular}{|c|c|c|c|c|c|c|c|c|}
\hline \multirow{2}{*}{ País } & \multicolumn{4}{|c|}{ Inversión pública } & \multicolumn{4}{|c|}{ Inversión privada } \\
\hline & 1980-1989 & 1990-1998 & 1999-2002 & $2003-2010$ & 1980-1989 & 1990-1998 & 1999-2002 & $2003-2010$ \\
\hline Argentina & 1,7 & 1,5 & 1,2 & 2,4 & 17,6 & 16,9 & 14,8 & 17,9 \\
\hline Bolivia (Estado Plurinacional de) & 8,0 & 7,4 & 5,3 & 7,4 & 4,1 & 8,6 & 11,4 & 7,4 \\
\hline Brasil & 2,2 & 2,7 & 1,7 & 1,8 & 16,4 & 15,4 & 14,2 & 15,5 \\
\hline Chile & 2,4 & 2,2 & 2,5 & 2,4 & 15,2 & 24,2 & 20,5 & 22,4 \\
\hline Colombia & 7,6 & 4,7 & 3,2 & 3,7 & 9,0 & 15,2 & 10,5 & 17,8 \\
\hline Cuba & .. & 7,1 & 6,8 & 9,1 & $\ldots$ & 4,7 & 5,0 & 2,4 \\
\hline Ecuador & $5 \ddot{7}$ & 4,2 & 5,1 & 7,3 & 12,6 & 20,7 & 17,6 & 19,7 \\
\hline El Salvador & 2,0 & 3,4 & 3,0 & 2,3 & 10,4 & 14,4 & 16,3 & 15,9 \\
\hline Guatemala & 3,5 & 3,0 & 3,4 & 2,6 & 6,1 & 7,4 & 12,2 & 14,7 \\
\hline Honduras & 7,7 & 7,7 & 5,1 & 3,9 & 9,0 & 14,1 & 19,8 & 20,8 \\
\hline México & 7,1 & 3,7 & 3,3 & 4,8 & 11,8 & 14,2 & 16,7 & 16,4 \\
\hline Nicaragua & 10,8 & 7,2 & 6,1 & 4,0 & 7,6 & 11,4 & 19,2 & 17,7 \\
\hline Panamá & 5,6 & 3,7 & 5,0 & 5,8 & 12,6 & 17,3 & 13,5 & 15,1 \\
\hline Perú & 5,4 & 4,3 & 3,7 & 3,9 & 15,1 & 16,3 & 15,3 & 18,6 \\
\hline República Dominicana & 4,1 & 3,3 & 2,3 & 1,5 & 14,7 & 15,6 & 20,7 & 17,7 \\
\hline Uruguay & 4,6 & 3,6 & 3,3 & 4,0 & 8,1 & 10,9 & 9,8 & 12,7 \\
\hline Venezuela (República Bolivariana de) & 11,4 & 9,6 & 9,0 & 15,7 & 9,5 & 8,1 & 15,4 & 12,0 \\
\hline América Latina ${ }^{a}$ & 5,6 & 4,6 & 4,0 & 4,6 & 11,7 & 14,3 & 15,0 & 15,7 \\
\hline
\end{tabular}

Fuente: elaboración propia sobre la base de cifras oficiales de los países y S. Manuelito y L.F. Jiménez, "La inversión y el ahorro en América Latina: Nuevos rasgos estilizados, requerimientos para el crecimiento y elementos para una estrategia para fortalecer su financiamiento", serie Macroeconomía del Desarrollo, N 129 (LC/L.3603), Santiago de Chile, Comisión Económica para América Latina y el Caribe (CEPAL), 2013.

a Corresponde al promedio simple de los países considerados.

PIB: producto interno bruto. 
indicador en 8 de los 19 países, pero en 13 de ellos la tasa de inversión persiste por debajo de los registros de los años ochenta ${ }^{4}$. Un tercer aspecto destacado es que, en contraste con el desempeño de la inversión pública, durante los años noventa la inversión privada aumentó en 14 de los 19 países. El desempeño de la inversión privada es heterogéneo desde el año 2003; en 8 países desciende en relación con los registros de 1999-2002, mientras que en 7 de ellos alcanza los mayores niveles del período examinado.

\footnotetext{
${ }^{4}$ La inversión pública se refiere a aquella realizada por el gobierno central, es decir, excluye aquella efectuada por empresas públicas, las que quedan incluidas en la inversión privada.
}

Por su parte, del análisis del cuadro 3 se desprende que, si bien la tasa de inversión en construcción en el período 1980-2010 muestra un comportamiento heterogéneo en los países, en varios casos tiende a presentar similitudes con la evolución de la inversión pública. Sin embargo, en promedio, el coeficiente de inversión en construcción se mantuvo relativamente estable alrededor del 10\% del PIB entre 1980 y 2010. A su vez, la inversión en maquinaria y equipo registra un desempeño relativamente similar al de la inversión privada; en los subperíodos 1990-1998 (15 de 19 países) y 2003-2010 (14 de 19 países) ella presenta un aumento con respecto al subperíodo anterior. Asimismo, en el subperíodo 2003-2010 se observa que el promedio regional tiene un nivel bastante superior al registrado en los años ochenta (9,6\% del PIB en comparación con $7,3 \%$ del PIB, respectivamente).

CUADRO 3

América Latina: formación bruta de capital fijo en construcción y maquinaria
y equipo como porcentaje del PIB, 1980-2010
(En moneda nacional a precios constantes)

\begin{tabular}{|c|c|c|c|c|c|c|c|c|}
\hline \multirow{2}{*}{ País } & \multicolumn{4}{|c|}{ Inversión en construcción } & \multicolumn{4}{|c|}{ Inversión en maquinaria y equipo } \\
\hline & 1980-1989 & 1990-1998 & 1999-2002 & $2003-2010$ & 1980-1989 & 1990-1998 & 1999-2002 & $2003-2010$ \\
\hline Argentina & 12,5 & 11,1 & 10,0 & 12,2 & 6,7 & 7,4 & 6,0 & 8,1 \\
\hline Bolivia (Estado Plurinacional de) & 6,2 & 8,1 & 8,6 & 8,0 & 5,9 & 7,9 & 8,1 & 6,8 \\
\hline Brasil & 12,6 & 12,7 & 10,6 & 10,2 & 5,9 & 5,5 & 5,3 & 7,1 \\
\hline Chile & 9,9 & 13,2 & 14,0 & 13,4 & 7,7 & 13,2 & 9,1 & 11,3 \\
\hline Colombia & 8,7 & 11,5 & 8,2 & 12,3 & 7,9 & 8,4 & 5,4 & 8,3 \\
\hline Costa Rica & 9,3 & 8,7 & 8,8 & 10,1 & 10,4 & 12,2 & 12,1 & 11,8 \\
\hline Cuba & $\ldots$ & 10,9 & 9,6 & 8,4 & $\ldots$ & 3,9 & 2,3 & 3,1 \\
\hline Ecuador & 9,8 & 12,3 & 13,4 & 15,5 & 8,6 & 12,7 & 9,2 & 11,6 \\
\hline El Salvador & 6,3 & 8,5 & 8,5 & 7,3 & 6,2 & 9,3 & 10,7 & 10,9 \\
\hline Guatemala & 4,7 & 4,5 & 6,5 & 7,3 & 5,0 & 5,9 & 9,1 & 10,0 \\
\hline Honduras & 10,6 & 11,5 & 10,1 & 7,4 & 6,1 & 10,4 & 14,8 & 17,3 \\
\hline México & 11,5 & 9,5 & 9,1 & 13,1 & 7,4 & 8,4 & 10,8 & 7,9 \\
\hline Nicaragua & 5,8 & 8,3 & 11,3 & 8,9 & 12,6 & 10,3 & 14,0 & 12,8 \\
\hline Panamá & 12,0 & 10,3 & 8,9 & 10,8 & 6,1 & 10,6 & 9,6 & 10,1 \\
\hline Paraguay & 13,5 & 11,3 & 9,5 & 9,1 & 8,4 & 11,6 & 7,2 & 8,8 \\
\hline Perú & 12,7 & 12,0 & 11,0 & 12,2 & 7,8 & 8,5 & 7,9 & 10,4 \\
\hline República Dominicana & 14,2 & 14,0 & 17,1 & 14,9 & 4,6 & 4,9 & 6,0 & 4,3 \\
\hline Uruguay & 8,4 & 7,8 & 7,5 & 8,9 & 4,3 & 6,7 & 5,5 & 7,5 \\
\hline Venezuela (República Bolivariana de) & 11,5 & 10,8 & 13,0 & 12,3 & 9,5 & 6,7 & 10,3 & 13,8 \\
\hline América Latina ${ }^{a}$ & 10,0 & 10,4 & 10,3 & 10,6 & 7,3 & 8,7 & 8,6 & 9,6 \\
\hline
\end{tabular}

Fuente: elaboración propia sobre la base de cifras oficiales de los países y S. Manuelito y L.F. Jiménez, "La inversión y el ahorro en América Latina: Nuevos rasgos estilizados, requerimientos para el crecimiento y elementos para una estrategia para fortalecer su financiamiento", serie Macroeconomía del Desarrollo, № 129 (LC/L.3603), Santiago de Chile, Comisión Económica para América Latina y el Caribe (CEPAL), 2013.

a Corresponde al promedio simple de los países considerados.

PIB: producto interno bruto. 


\section{Factores que incidieron en el aumento de la inversión durante los subperíodos 1990-1998 y 2003-2010}

Si bien el objetivo de este artículo no es construir un modelo que establezca econométricamente la contribución o el impacto de diversos factores en la evolución observada de la tasa de inversión en el período bajo análisis, de los diversos análisis que continuamente realiza la CEPAL se desprende un conjunto de elementos que contribuyen a una explicación del fenómeno ${ }^{5}$. Así, la mayor disponibilidad de financiamiento en divisas y la consiguiente menor incidencia de las restricciones externas al crecimiento fueron uno de los factores que contribuyeron a la moderada expansión de la tasa de inversión en los subperíodos 1990-1998 y 2003-2010. Ello también influyó en el alza de la tasa de inversión en maquinaria y equipo.

En el período 1990-1998, se registró una creciente apertura externa de la mayoría de las economías de América Latina (algunas habían iniciado esta estrategia con anterioridad, en el segundo lustro de los años ochenta). Esto se tradujo en la apertura de ciertos sectores a la inversión extranjera directa (IED) y en los procesos de privatización de los servicios de utilidad pública y la banca, lo que generó un aumento de los flujos de IED hacia la región. La apertura se extendió también al ámbito del comercio exterior y se incrementaron los procesos de integración comercial. Ejemplos de ello son el Tratado de Libre Comercio de América del Norte (TLCAN), el Mercado Común del Sur (MERCosur) y la instalación de industrias maquiladoras en los países de Centroamérica. Estos procesos indujeron un incremento de la inversión así como de las exportaciones de bienes, principalmente a través de una expansión en los volúmenes de bienes exportados ${ }^{6}$.

Junto con el aumento de las exportaciones, en el subperíodo 1990-1998 se registró una disminución en los precios internacionales de las manufacturas y un alza de los precios internacionales de algunas materias primas antes de que detonara la crisis asiática en $1997^{7}$, lo que

\footnotetext{
${ }^{5}$ Esta discusión se apoya en los análisis y evidencias presentadas en las ediciones del Estudio Económico de América Latina y el Caribe publicado por la CEPAL en forma anual.

${ }^{6}$ Como la actividad de la maquila implicó también un aumento importante de las importaciones de bienes, el incremento de las exportaciones de bienes repercutió de forma limitada en la mejoría de los saldos de la balanza comercial de los países latinoamericanos.

7 En particular, los precios internacionales de la carne, el café, la soja y el trigo. El comportamiento de los metales y minerales fue más volátil, aunque de 1993 a 1995 los precios internacionales del
}

se tradujo en un acrecentamiento del poder de compra de las exportaciones regionales ${ }^{8}$. Estos incrementos se observaron en México y los países de Centroamérica, el primero beneficiado por la puesta en marcha del TLCAN, y los segundos por las inversiones relacionadas con las industrias maquiladoras ${ }^{9}$. A pesar del mayor ingreso de divisas, se mantuvieron las características que se observaban hasta entonces del financiamiento de la inversión regional. Como se describe más adelante, en el subperíodo 1990-1998 se acentuó la dependencia del financiamiento de la inversión basado en el ahorro externo, en detrimento de su financiamiento sobre la base del ahorro nacional, lo que fue apoyado por el mayor acceso de las economías de la región al financiamiento externo (véase el cuadro 7).

A lo anterior se suma un segundo factor que facilitó el aumento en la inversión, y específicamente de la inversión en maquinaria y equipo. La afluencia de divisas a las economías de la región, como producto de las mayores exportaciones y del incipiente desarrollo del mercado financiero en varios países, contribuyó a apreciaciones cambiarias que abarataron los costos en moneda nacional de los bienes importados. Esto es relevante dada la elevada participación de bienes de capital importados en la inversión en maquinaria y equipo de los países de la región. En cuatro países (Argentina, Brasil, Ecuador y México), la apreciación real fue todavía más acentuada por los programas antiinflacionarios que emplearon el tipo de cambio como "ancla" nominal.

Lo anterior se combinó con tendencias a la disminución de los precios internacionales de los bienes de capital ${ }^{10}$, que se manifestaron desde los años ochenta y con mayor intensidad en los años noventa. Los precios

aluminio, cobre y níquel acumularon incrementos superiores al 50\%. Posteriormente, con el inicio de la crisis asiática, los precios de las materias primas registraron disminuciones generalizadas y su bajo nivel se mantuvo hasta 2003.

${ }^{8}$ El poder de compra de las exportaciones se puede definir como el valor de las exportaciones de bienes medido en términos de su capacidad de compra de importaciones de bienes. En otras palabras, corresponde al volumen de exportaciones multiplicado por la relación de los términos de intercambio. La siguiente expresión lo sintetiza:

$$
P C E=Q x *\left(\frac{P x}{P m}\right)
$$

donde:

$Q x=$ es el índice de volumen de las exportaciones de bienes.

$P x=$ es el índice de precios de las exportaciones de bienes.

$P m=$ es el índice de precios de las importaciones de bienes.

${ }^{9}$ No obstante, en ambos casos debe tenerse presente que el componente importado de las exportaciones de bienes era bastante elevado, con lo que el aumento en el ingreso nacional proveniente de las mayores exportaciones de bienes fue muy acotado.

${ }^{10}$ Corresponde al índice de bienes de capital excepto los automóviles. 
internacionales de los bienes de capital disminuyeron un $23 \%$ de 1980 a 1990 y anotaron una caída adicional de un $42 \%$ de 1990 a 2000, tomando como referencia el índice de valor unitario de las importaciones de bienes de capital de los Estados Unidos de América, elaborado por el Bureau of Economic Analysis (véase el gráfico 3) ${ }^{11}$.

El ciclo de expansión de la inversión fue interrumpido en 1997-1998 por el inicio de la crisis asiática. Entre 1990 y 1998, en varios países el aumento de la demanda interna había redundado en desequilibrios en cuenta corriente de la balanza de pagos, que no fueron sostenibles cuando sobrevino la restricción de financiamiento externo. Como consecuencia de ello, en varios países se aplicaron ajustes en la demanda interna, que explican la disminución observada en las tasas de inversión desde 1999 hasta 2002, que fue más intensa en la tasa de inversión en maquinaria y equipo.

Durante los años 2003 a 2010, el segundo subperíodo en el que se verificaron aumentos en los coeficientes de inversión, se registró un importante cambio en relación con las tendencias del subperíodo 1998-2002. A partir de la segunda mitad de 2003, en varios países hubo un incremento significativo del ingreso nacional bruto disponible, que incidió en el engrosamiento del ahorro nacional, tanto público como privado, que se explica

${ }^{11}$ Este índice se considera aquí solo como una referencia de los precios internacionales de los bienes de capital relevantes para la región, por cuanto la estructura de las importaciones de esta categoría de bienes de los Estados Unidos de América no necesariamente coincide con las de los países latinoamericanos. sobre todo por mejorías acentuadas de los términos de intercambio a consecuencia de la súbita elevación de los precios internacionales de las materias primas (véase el cuadro 4).

El análisis de la evolución del ahorro nacional privado y del ahorro nacional público presenta ciertos problemas de comparación entre los países, dado que en algunos se calcula el ahorro neto (esto es, neto del consumo de capital fijo), en tanto que en otros se estima el ahorro bruto. La comparación de ambas definiciones no es exacta, pero en el transcurso del tiempo su desempeño arroja luces en cuanto a los aspectos macroeconómicos del financiamiento de la inversión (véanse los cuadros 5 y 6 ).

Si bien la disponibilidad de datos no es similar en el tiempo, en ambos subperíodos en que aumentó el coeficiente de ahorro público, lo hizo tanto en relación con el período previo como respecto de lo observado en el período 1980-1989. El incremento del ahorro público fue más elevado durante el subperíodo 2003-2010, en especial en el caso de los países en que los recursos provenientes de la explotación y exportación de recursos naturales tienen una alta incidencia en sus ingresos fiscales: Argentina, Bolivia (Estado Plurinacional de), Chile, Ecuador, Perú y Venezuela (República Bolivariana de), con la excepción de México ${ }^{12}$.

12 Véase CEPAL (2011, cuadro I.2) donde se ilustra, para varios países, la creciente incidencia en los ingresos fiscales de los ingresos vinculados a bienes primarios.

GRÁFICO 3

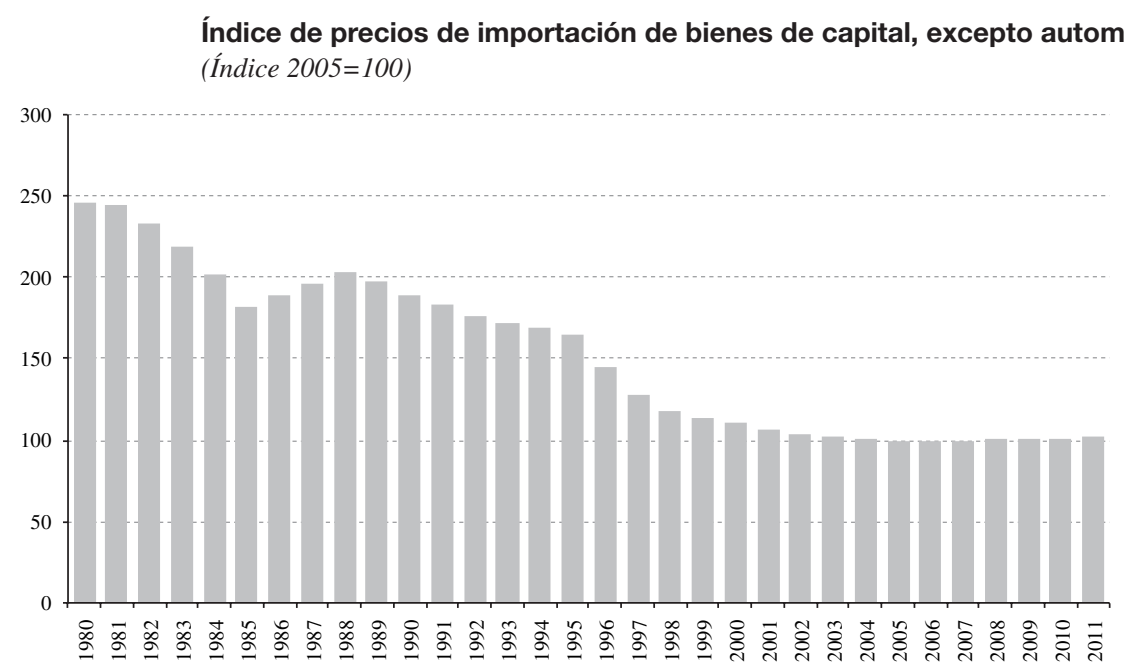

Fuente: elaboración propia sobre la base de datos del Bureau of Economic Analysis del Departamento de Comercio de los Estados Unidos de América. 
CUADRO 4

América Latina: ahorro nacional como porcentaje del PIB, 1980-2010

(En moneda nacional a precios corrientes)

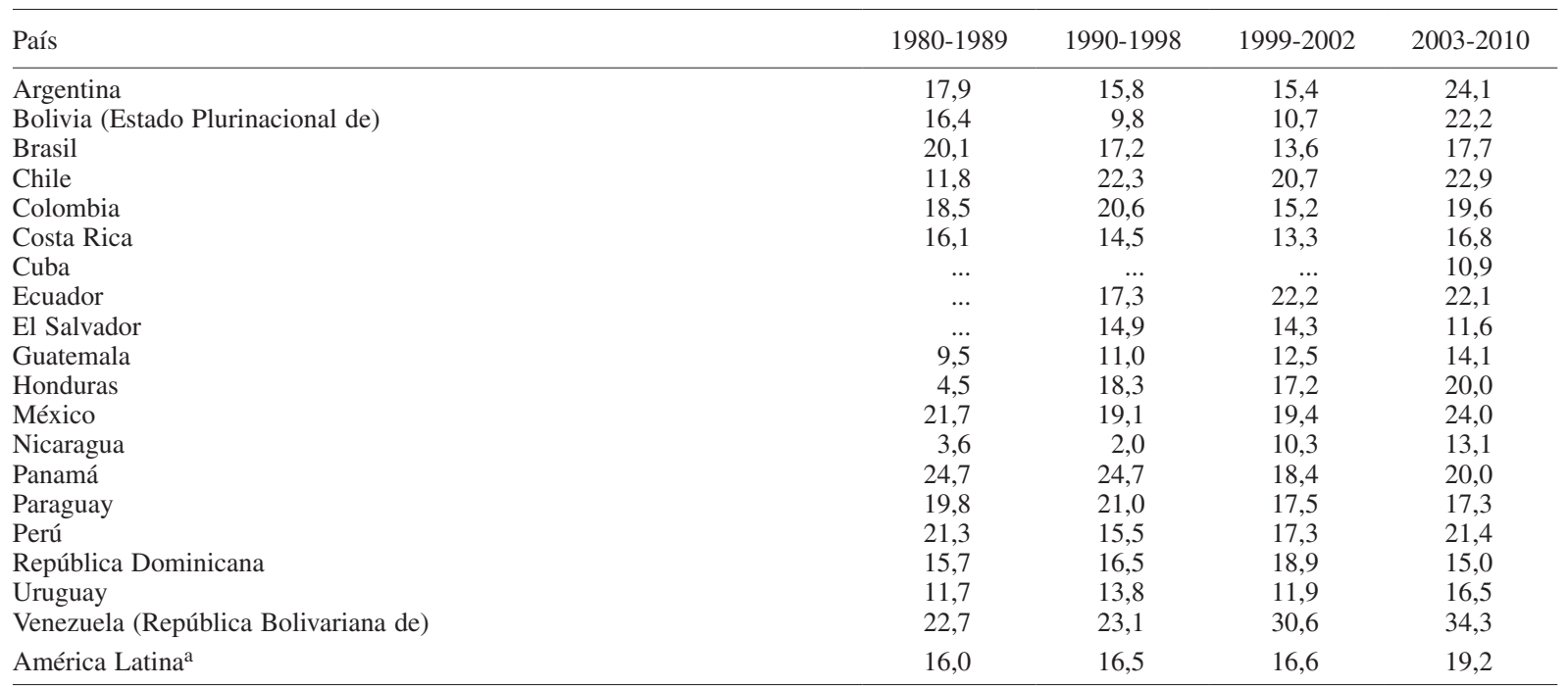

Fuente: elaboración propia sobre la base de cifras oficiales de los países y S. Manuelito y L.F. Jiménez, "La inversión y el ahorro en América Latina: Nuevos rasgos estilizados, requerimientos para el crecimiento y elementos para una estrategia para fortalecer su financiamiento", serie Macroeconomía del Desarrollo, N 129 (LC/L.3603), Santiago de Chile, Comisión Económica para América Latina y el Caribe (CEPAL), 2013.

a Corresponde al promedio simple de los países considerados.

PIB: producto interno bruto.

CUADRO 5

América Latina: ahorro público como porcentaje del PIB, 1980-2010

(En moneda nacional a precios corrientes)

\begin{tabular}{lrrr}
\hline País & $1980-1989$ & $1990-1998$ & $1999-2002$ \\
\hline
\end{tabular}

I. Países que reportan ahorro público bruto

Argentina
Bolivia (Estado Plurinacional de)
Brasil
Colombia
Cuba
El Salvador
Guatemala
Nicaragua
República Dominicana
Uruguay
Promedio

II. Países que reportan ahorro público neto

\begin{tabular}{|c|c|c|c|}
\hline Chile & $\ldots$ & 4,4 & 0,8 \\
\hline Costa Rica & 3,2 & 2,4 & 2,6 \\
\hline Ecuador & $\ldots$ & 4,9 & 3,5 \\
\hline Honduras & $\ldots$ & 1,0 & 2,6 \\
\hline México & $\ldots$ & 4,1 & 1,6 \\
\hline Panamá & $-2,8$ & 3,0 & 0,7 \\
\hline Paraguay & 1,2 & 2,6 & 1,4 \\
\hline Perú & $-1,7$ & 0,6 & $-0,3$ \\
\hline Venezuela (República Bolivariana de) & $\ldots$ & 9,2 & 1,4 \\
\hline Promedio $^{\mathrm{a}}$ & 0,0 & 3,6 & 1,6 \\
\hline
\end{tabular}

Fuente: elaboración propia sobre la base de cifras oficiales de los países y S. Manuelito y L.F. Jiménez, "La inversión y el ahorro en América Latina: Nuevos rasgos estilizados, requerimientos para el crecimiento y elementos para una estrategia para fortalecer su financiamiento", serie Macroeconomía del Desarrollo, N 129 (LC/L.3603), Santiago de Chile, Comisión Económica para América Latina y el Caribe (CEPAL), 2013.

a Corresponde al promedio simple de los países considerados.

PIB: producto interno bruto. 
América Latina: ahorro privado como porcentaje del PIB, 1980-2010a

(En moneda nacional a precios corrientes)

\begin{tabular}{|c|c|c|c|c|}
\hline País & 1980-1989 & 1990-1998 & 1999-2002 & $2003-2010$ \\
\hline \multicolumn{5}{|l|}{ I. Países que reportan ahorro privado bruto } \\
\hline Argentina & & 16,8 & 16,9 & 21,6 \\
\hline Bolivia (Estado Plurinacional de) & 20,2 & 7,2 & 12,5 & 17,9 \\
\hline Brasil & & 11,6 & 12,3 & 17,2 \\
\hline Colombia & 16,1 & 17,0 & 16,9 & 18,8 \\
\hline Cuba & $\ldots$ & $\ldots$ & $\ldots$ & $\ldots$ \\
\hline El Salvador & $\ldots$ & 13,6 & 14,1 & 11,7 \\
\hline Guatemala & $\ldots$ & 9,2 & 10,2 & 11,8 \\
\hline Nicaragua & $\ldots$ & 0,8 & 10,0 & 12,0 \\
\hline República Dominicana & $\ldots$ & 12,7 & 15,6 & 12,9 \\
\hline Uruguay & 11,9 & 10,5 & 14,1 & 15,6 \\
\hline Promedio $^{\mathrm{a}}$ & 16,1 & 11,1 & 13,6 & 15,5 \\
\hline \multicolumn{5}{|l|}{ II. Países que reportan ahorro privado neto } \\
\hline Chile & $\ldots$ & 7,3 & 6,7 & 5,8 \\
\hline Costa Rica & 9,6 & 6,8 & 4,9 & 7,9 \\
\hline Ecuador & $-3,1$ & 11,6 & 16,8 & 14,0 \\
\hline Honduras & $\ldots$ & 17,3 & 14,7 & 15,5 \\
\hline México & .. & 5,2 & 8,1 & 12,9 \\
\hline Panamá & 20,6 & 14,7 & 9,6 & 11,7 \\
\hline Paraguay & 8,2 & 13,9 & 11,9 & 12,6 \\
\hline Perú & 17,2 & 8,4 & 10,4 & 12,1 \\
\hline Venezuela (República Bolivariana de) & .. & 7,2 & 23,1 & 23,8 \\
\hline Promedio $^{\mathrm{a}}$ & 10,5 & 10,3 & 11,9 & 12,6 \\
\hline
\end{tabular}

Fuente: elaboración propia sobre la base de cifras oficiales de los países y S. Manuelito y L.F. Jiménez, "La inversión y el ahorro en América Latina: Nuevos rasgos estilizados, requerimientos para el crecimiento y elementos para una estrategia para fortalecer su financiamiento", serie Macroeconomía del Desarrollo, № 129 (LC/L.3603), Santiago de Chile, Comisión Económica para América Latina y el Caribe (CEPAL), 2013.

a Corresponde al promedio simple de los países considerados.

PIB: producto interno bruto.

Diversas razones explican este comportamiento del ahorro público. Un factor común a varios países es, tal como se mencionó anteriormente, el aumento del ingreso nacional derivado de la mejoría sostenida en los términos de intercambio en el subperíodo 2003-2010. Además, durante estos años se adoptaron progresivamente políticas fiscales orientadas a reforzar la sostenibilidad de las finanzas públicas durante el ciclo completo de precios de las materias primas, en coincidencia con un incremento significativo de los precios de estos bienes ${ }^{13}$. En el caso de la Argentina y el Ecuador, el aumento del ahorro público se relacionó también con la necesidad de enfrentar las consecuencias del acceso restringido al financiamiento externo.

El ahorro privado medido como porcentaje del PIB también registra alzas importantes, mayores durante el

13 Véase CEPAL (2011, recuadro I.1) en que se describe la progresiva adopción de reglas fiscales en la región a partir de 2000. Además, en el recuadro III.1 se presentan las principales características de los fondos orientados a moderar el impacto de las fluctuaciones en los ingresos públicos vinculados a bienes primarios. subperíodo 2003-2010, que corresponde al segundo subperíodo en que la tasa de inversión mantuvo una tendencia al alza. Esta evolución se relaciona con el incremento en el ingreso nacional bruto disponible en los países de la región y se observa en dos tercios de ellos (véanse los cuadros 5 y 6). En ciertos casos, dicho aumento del ahorro privado incluye ahorros de empresas públicas que no fueron transferidos al gobierno central. Nótese que, a pesar de que la gran mayoría de los países muestran una tendencia creciente en el ahorro privado, en El Salvador, Chile, el Paraguay y la República Dominicana se registra una disminución de este indicador (véase el cuadro 6).

La evolución del ahorro privado y del ahorro público contribuye a explicar el aumento del ahorro nacional que se aprecia en el subperíodo 1990-1997 y, en especial, de 2003 a 2008, años en que se registraron alzas sostenidas del coeficiente de inversión. Además, en varios países el incremento del ahorro nacional fue superior al de la inversión, lo que redundó en una aguda caída de la participación del ahorro externo en el financiamiento de la inversión en más de la mitad de los 
países considerados (véase el cuadro 7). Asimismo, se observa que al comparar el subperíodo 2003-2008 con relación al subperíodo anterior (1999-2002), el aumento del ahorro público medido como porcentaje del PIB fue mayor que el del ahorro privado, también como porcentaje del PIB $^{14}$ en 8 de los 19 países analizados. Sin embargo, estas mayores alzas del ahorro público no se reflejaron en incrementos similares de la inversión pública.

De lo anterior se puede concluir que, además de factores exógenos a los países de la región (mayores precios de las exportaciones de materias primas, engrosamiento de las remesas de emigrantes, disminución de las tasas de interés de la deuda externa) que aportaron al alza del ingreso nacional bruto disponible en el subperíodo 2003-2010, también influyeron en el menor recurso al ahorro externo las políticas en materia de sostenibilidad de las finanzas públicas y de manejo de las reservas internacionales. En efecto, la contrapartida de un menor uso del ahorro externo estuvo en la reducción del endeudamiento externo como proporción del PIB, en

${ }^{14}$ En aquellos casos en que se observaron disminuciones del ahorro público y privado, la reducción del ahorro público fue menor que la del ahorro privado. la significativa acumulación de reservas internacionales netas, y en los ahorros públicos acumulados en fondos soberanos en varios de los países de la región ${ }^{15}$. Desde esta perspectiva, el rasgo de mayor contraste entre la coyuntura económica de los subperíodos 1990-1998 y 2003-2010 fue la mayor participación del ahorro nacional en el financiamiento de la inversión regional durante el segundo subperíodo, lo que representó un cambio hacia una mayor sostenibilidad del crecimiento y una menor vulnerabilidad frente a las vicisitudes de los mercados financieros externos. Cuando sobrevino la crisis financiera global de 2008-2009, el menor recurso al ahorro externo producto del mayor ahorro nacional en los años previos posibilitó en varios países la acción de políticas contracíclicas y que la región en general enfrentara esta contingencia en una mejor condición, con menos pérdidas de crecimiento que en experiencias previas.

\footnotetext{
15 Recuérdese, además, que durante este período algunos países (por ejemplo, el Brasil y la Argentina) pagaron sus obligaciones con el Fondo Monetario Internacional (FMI) en forma anticipada. También en Chile se adoptó una política de prepago de sus créditos a instituciones multilaterales de 2004 a 2006 y, al igual que en otros países, se hizo una recompra de una parte de sus bonos externos.
}

América Latina: ahorro externo como porcentaje del PIB, 1980-2010 (En moneda nacional a precios corrientes)

\begin{tabular}{lrrrr}
\hline País & $1980-1989$ & $1990-1998$ & $1999-2002$ & $2003-2010$ \\
\hline Argentina & 2,1 & 2,7 & 0,1 & $-2,7$ \\
Bolivia (Estado Plurinacional de) & $-1,6$ & 6,9 & 4,7 & $-7,3$ \\
Brasil & 2,1 & 1,8 & 3,6 & 0,3 \\
Chile & 7,1 & 3,2 & 0,9 & $-1,6$ \\
Colombia & 1,3 & 1,1 & 0,0 & 1,9 \\
Costa Rica & 9,5 & 5,5 & 5,9 & 6,1 \\
Cuba & $\ldots$ & $\ldots$ & 1,0 \\
Ecuador & $\ldots$ & 4,4 & $-0,8$ & 2,1 \\
El Salvador & $\ldots$ & 2,2 & 2,3 & 3,9 \\
Guatemala & 3,8 & 3,4 & 6,4 & 4,1 \\
Honduras & 6,8 & 5,6 & 5,7 & 6,7 \\
México & 0,5 & 3,8 & 2,8 & 0,7 \\
Nicaragua & 17,0 & 23,2 & 20,6 & 16,0 \\
Panamá & $-6,7$ & $-0,1$ & 2,5 & 1,2 \\
Paraguay & $-5,0$ & 0,8 & 1,7 & $-2,5$ \\
Perú & 3,6 & 5,9 & 2,3 & 0,1 \\
República Dominicana & 5,6 & 1,8 & 3,1 & 3,0 \\
Uruguay & 2,1 & 1,3 & 1,7 & $-2,5$ \\
Venezuela (República Bolivariana de) & $-2,0$ & $-3,3$ & $-5,8$ & $-9,9$ \\
América Latina & 2,9 & 3,9 & 3,2 & 1,3 \\
\hline
\end{tabular}

Fuente: elaboración propia sobre la base de cifras oficiales de los países y S. Manuelito y L.F. Jiménez, "La inversión y el ahorro en América Latina: Nuevos rasgos estilizados, requerimientos para el crecimiento y elementos para una estrategia para fortalecer su financiamiento", serie Macroeconomía del Desarrollo, $\mathrm{N}^{\circ} 129$ (LC/L.3603), Santiago de Chile, Comisión Económica para América Latina y el Caribe (CEPAL), 2013.

a Corresponde al promedio simple de los países considerados.

PIB: producto interno bruto. 
En un escenario de variaciones acotadas en los precios internacionales de las manufacturas, el aumento del ahorro nacional se expresó en una nueva alza del poder de compra de las exportaciones (véase el gráfico 4). Este fenómeno fue más pronunciado en las economías de América del Sur, dada su mayor especialización en la producción y exportación de materias primas.

A lo anterior se sumó durante el subperíodo 20032010 la reanudación de la tendencia a las apreciaciones de las monedas nacionales en cinco países (Brasil, Chile, Colombia, México y Perú) abaratando, entre otras cosas, la importación de bienes de capital. No obstante, la evolución de los precios internacionales de los bienes de capital no desempeñó en esos años un papel tan preponderante como en el subperíodo 1990-1998. Aunque estos precios mantuvieron su tendencia a la disminución, desde 2002 las variaciones fueron bastante inferiores; de 2002 a 2011 la tasa de variación de este índice fue de un $-6,4 \%$. Sin embargo, es destacable que en 2005 los precios de los bienes de capital se situaban en un nivel equivalente al $40 \%$ de aquellos registrados en 1980. Así, una coyuntura en que se verifican mejoras en los términos de intercambio, disminución de los precios de los bienes de capital y apreciaciones cambiarias, contribuyó a un aumento del ahorro nacional medido en dólares. Esto, junto con el dinamismo del crecimiento de esos años, generó condiciones para el mayor incremento de la inversión en maquinaria y equipo.

GRÁFICO 4
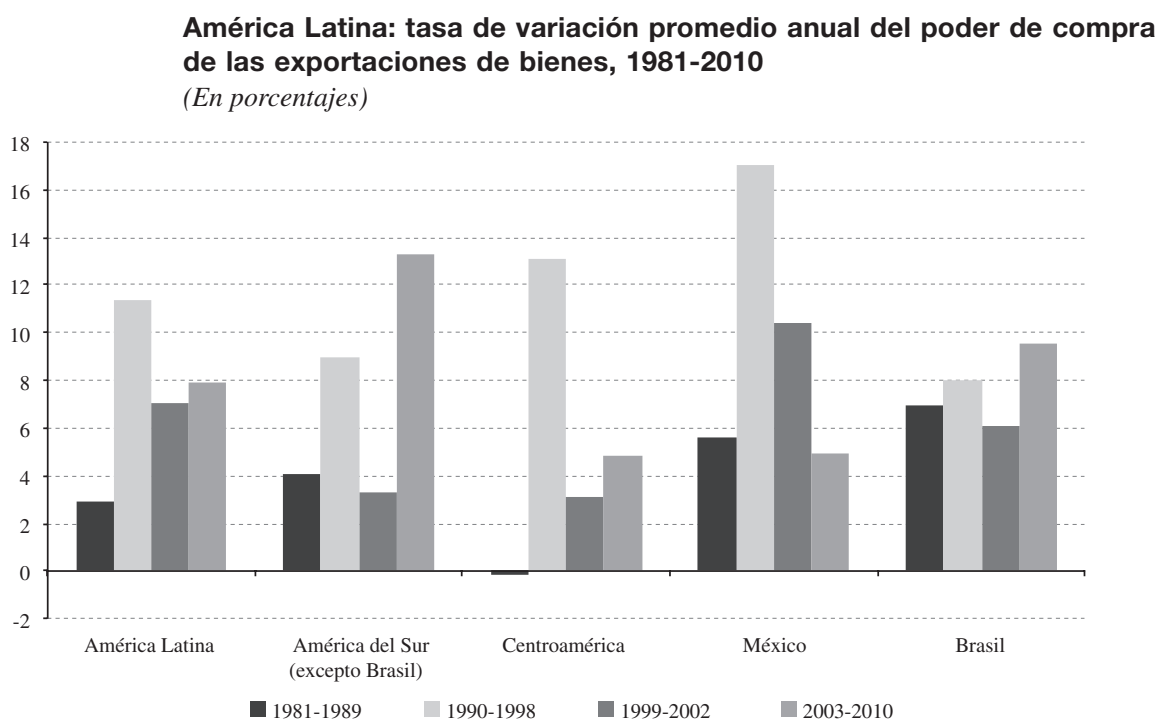

Fuente: elaboración propia sobre la base de Comisión Económica para América Latina y el Caribe (CEPAL), base de datos CEPALSTAT.

Nota: el promedio para América Latina corresponde al promedio ponderado regional. Cada país recibe una ponderación igual a su participación relativa en las exportaciones regionales. El promedio para cada una de las subregiones corresponde a un promedio simple.

\section{III}

\section{Una aproximación empírica a la relación entre crecimiento e inversión en América Latina}

En esta sección, empleando los datos descritos y analizados en el punto anterior, se examina empíricamente la relación entre la tasa de inversión y el crecimiento en los países de América Latina desde 1980 hasta 2010.
Desde una perspectiva de largo plazo, en la teoría económica se plantea que en el logro de un determinado nivel de actividad desempeñan un papel fundamental la acumulación de factores, el progreso técnico y, en 
ciertos enfoques como el propuesto por la CEPAL, se enfatizan además las características de la estructura productiva. En los estudios empíricos se señala que la acumulación de capital productivo, si bien constituye una condición necesaria para el crecimiento, no es suficiente. El examen de esta relación ha sido muy amplio; un buen resumen al respecto es el trabajo de Sala-i-Martin (1997). En ese estudio —utilizando métodos robustos de estimación - se identifican al menos 22 variables que están significativamente correlacionadas con el crecimiento económico. Entre estas figura con una alta incidencia la inversión en maquinaria y equipo, en contraste con la baja repercusión de otras inversiones (por ejemplo, la construcción). También destacan por su elevada influencia las distorsiones del tipo de cambio real y el diferencial del tipo de cambio oficial y del mercado negro (ambas variables con coeficientes negativos) (Sala-i-Martin, 1997).

En estudios recientes se abordan otros dos aspectos clave: el efecto en el crecimiento económico de la inversión pública y de la inversión extranjera directa (IED). En ambos casos se reporta una incidencia positiva (Toulaboe, Terry y Johansen, 2009; Cullison, 1993; Bukhari, Ali y Saddaqat, 2007).

En contraste, desde una perspectiva de corto y mediano plazo, el nivel de actividad económica y su dinamismo son considerados como resultados de los niveles de demanda agregada, los precios relativos clave y las restricciones provenientes de la oferta.

Esta dicotomía en los análisis teóricos según su horizonte temporal contrasta con los resultados de los análisis empíricos del crecimiento económico, la experiencia de los países y la práctica de la política económica, para los cuales las políticas adoptadas en el corto plazo gravitan sobre el resultado en el largo plazo. En efecto, en el corto y mediano plazo, el énfasis en la importancia de la inversión descansa más en aspectos vinculados con la demanda. La inversión constituye un factor dinamizador de la demanda agregada (efecto multiplicador) y contribuye de forma decisiva a determinar su nivel, en especial aquella con alto efecto en el empleo. Paralelamente, las expectativas de crecimiento presente y futuro potencian el dinamismo de la inversión (efecto acelerador). La naturaleza de largo plazo de las decisiones de inversión hace que las expectativas de rentabilidad y crecimiento sean factores muy relevantes. Por esta razón, un buen desempeño en el presente, en un escenario de crecimiento sostenible, entendiéndose este último como un desempeño económico no sujeto a desequilibrios fuertes y prolongados, contribuye a generar expectativas positivas que favorecen las decisiones presentes sobre inversiones futuras, permitiendo elevar la trayectoria del crecimiento.

No obstante, en diversos estudios empíricos se plantea que las relaciones de causalidad de corto a mediano plazo entre el crecimiento del PIB y la tasa de inversión pueden ser mutuas (Blomström, Lipsey y Zehjan, 1993; Peltonen, Sousa y Vansteenkiste, 2012; Cheung, Dooley y Sushko, 2012). De este modo, el aumento de la inversión contribuye a la expansión de la actividad económica a través del impacto positivo en la demanda, lo que a su vez estimula la inversión por el camino de la reducción de la capacidad ociosa y mejorías en las expectativas de rentabilidad futura.

De acuerdo con lo señalado en los dos párrafos previos, el examen empírico de la relación entre inversión y crecimiento que se realiza a continuación se enmarca en una perspectiva de corto plazo y no se descartan causalidades mutuas. En razón de ello se emplea una metodología distinta a los análisis empíricos del crecimiento de largo plazo ${ }^{16}$. Centrar el interés del análisis en la relación de corto plazo entre la tasa de inversión y el crecimiento permite resaltar la relevancia de las políticas contracíclicas y de prevención de crisis para sostener o elevar la tasa de inversión. Esto último, a su vez, hace posible vincular la política macroeconómica con el crecimiento de largo plazo, tema cuya relevancia es evidente en la práctica y en la literatura.

En la literatura empírica, la relación de causalidad entre el crecimiento y la inversión es aún un tema de debate. Los resultados obtenidos no son concluyentes y dependen en gran medida del período de tiempo considerado, de la economía estudiada y de consideraciones tales como el número de rezagos con el que se obtienen las estimaciones, o el mismo método de estimación. Además, estos ejercicios se ven dificultados por el hecho de que, ex post, el vínculo de estas variables se inserta en las relaciones de identidades de las cuentas nacionales, por lo que surgen problemas de simultaneidad de las variables y se torna más compleja la demostración de la existencia de causalidades en un sentido u otro. Teniendo presentes esas limitaciones, se exploró la existencia de relaciones de causalidad (en el sentido de Granger) entre la tasa de variación del PIB y el coeficiente de inversión. A continuación se presentan los resultados, incluyéndose

\footnotetext{
${ }^{16}$ Es plausible que los efectos totales de la inversión en el crecimiento se materialicen durante plazos más largos que los aquí analizados. No obstante, la cuantificación de esos efectos supone una metodología distinta a la empleada en este estudio, así como la disponibilidad de series estadísticas con un mayor número de observaciones. Para un análisis reciente del crecimiento de largo plazo en América Latina y el Caribe, véase CEPAL (2014, cap. III).
} 
solo un rezago en las variables. Se realizaron ejercicios con un número mayor de rezagos, pero fue al aplicar rezagos de orden 1 que se obtuvieron resultados significativos para mayor cantidad de países ${ }^{17}$.

Se testearon dos hipótesis nulas:

i) Hipótesis nula (1): la tasa de inversión no causa (en el sentido de Granger) la tasa de variación del PIB. El rechazo de la hipótesis nula (1) se interpreta como el hecho de que los cambios en el coeficiente de inversión preceden a cambios en la tasa de crecimiento del PIB.

ii) Hipótesis nula (2): la tasa de variación del PIB no causa (en el sentido de Granger) el coeficiente de inversión. El rechazo de la hipótesis nula (2) se interpreta como el hecho de que los cambios en la tasa de crecimiento del PIB preceden a cambios en el coeficiente de inversión.

Para efectos de simplificación, a continuación se llamará $\operatorname{Hn}(1)$ a la hipótesis nula (1) y $\operatorname{Hn}(2)$ a la hipótesis nula (2).

En el cuadro 8 se presentan los resultados obtenidos al testear $\mathrm{Hn}(1)$, la que examina la existencia de causalidad en el corto plazo desde la tasa de inversión, la tasa de inversión pública, la tasa de inversión privada, la tasa de inversión en construcción y la tasa de inversión en maquinaria y equipo hacia la tasa de crecimiento del PIB.

Los resultados obtenidos de las pruebas realizadas sugieren que, en general, no es posible rechazar $\mathrm{Hn}(1)$, con ciertas excepciones. En efecto, de los 18 países estudiados, en 14 casos con al menos un $95 \%$ de significancia no se rechaza $\mathrm{Hn}(1)$, lo que puede interpretarse como la ausencia de evidencias de causalidad en el corto plazo desde la tasa de inversión hacia el PIB. Excepciones a

\footnotetext{
${ }^{17} \mathrm{Al}$ aplicar un mayor número de rezagos, se mantiene igualmente la interpretación de los resultados obtenidos al usar rezagos de orden 1 , aunque con un menor nivel de significancia. Los resultados cualitativos no se ven modificados en el sentido de que no se detectan reversiones de signo, por lo que no se obtiene conocimiento adicional respecto de la relación entre ambas variables. Además, si bien estas series desagregadas son las de mayor longitud disponible, solo corresponden a 30 observaciones, por lo que incluir un número mayor de rezagos implica una pérdida de grados de libertad para el análisis econométrico. En consecuencia, se considera preferible reportar los ejercicios más simples, los que podrán ser fácilmente replicados y contrastados por otros investigadores una vez que se difunda la base de datos.
}

este resultado son los casos de la Argentina, el Brasil, Costa Rica y Panamá en los cuales sí habría existido esa causalidad durante el período analizado. Si se acepta un 90\% de significancia, a los anteriores casos se agregaría el de la República Bolivariana de Venezuela.

La ausencia de un efecto de corto plazo en el crecimiento tiende a mantenerse en el examen de causalidad desde la inversión pública, privada y en maquinaria y equipo hacia el PIB. En contraste, en el caso de la inversión en construcción, el número de países en que se rechaza $\mathrm{Hn}(1)$ sube a 8 , por lo que, en esos casos, habría existido con una relación de causalidad desde la inversión en construcción hacia el crecimiento.

En el cuadro 9 se presentan los resultados de la prueba de $\mathrm{Hn}(2)$, que examina la existencia de causalidad en el corto plazo desde la tasa de crecimiento del PIB hacia las tasas de inversión total, de inversión pública y privada, y hacia las tasas de inversión en construcción y en maquinaria y equipo. Como allí se aprecia, en 9 de los 18 países estudiados, con al menos un $95 \%$ de significancia, es posible rechazar la hipótesis de no causalidad desde el crecimiento del PIB hacia la inversión total, número que se eleva a 13 si se acepta un $90 \%$ de significancia. Esto implica que para varios países de la región, y con una alta probabilidad, los cambios en la tasa de crecimiento del PIB han precedido y repercutido positivamente en los cambios en el coeficiente de inversión durante el período estudiado. Excepciones a estos resultados son los casos del Brasil, Chile, el Ecuador, Guatemala y México.

En relación con los efectos del crecimiento del PIB en los componentes de la inversión, en poco más de la mitad de los casos se aprecia una relación de causalidad desde el crecimiento del PIB hacia la inversión privada, hacia aquella en maquinaria y equipos y en especial hacia la inversión en construcción. En contraste, en el caso de la inversión pública, no se aprecian evidencias de causalidad desde el crecimiento del PIB.

Si se comparan los resultados presentados en los cuadros 8 y 9 se aprecia que en varios casos (Argentina, Costa Rica y Panamá) se rechazan ambas hipótesis, con lo que la causalidad entre estas variables (en el sentido de Granger) sería bidireccional, otorgando cierto sustento a los estudios señalados anteriormente. No obstante, una prueba formal requiere de un ejercicio diferente del aquí realizado. 


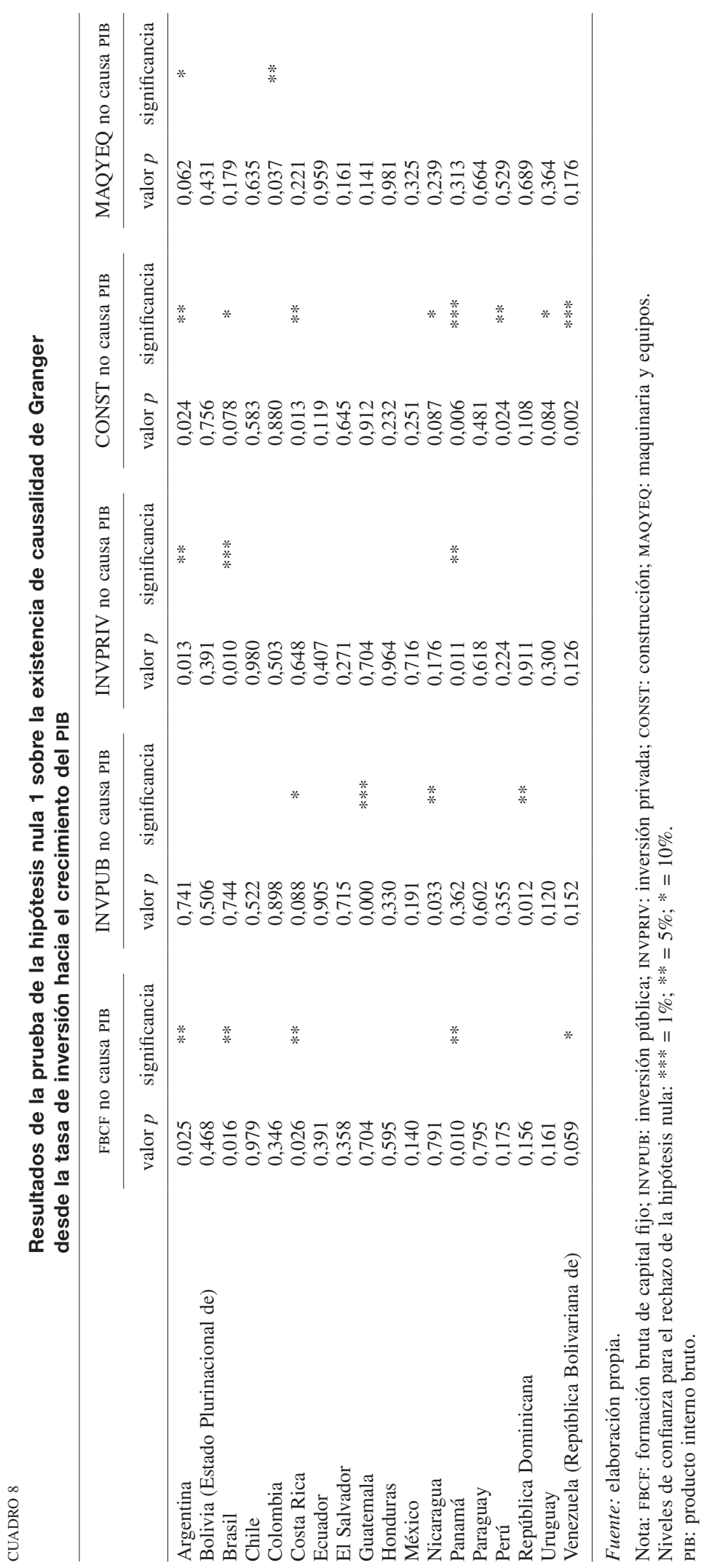




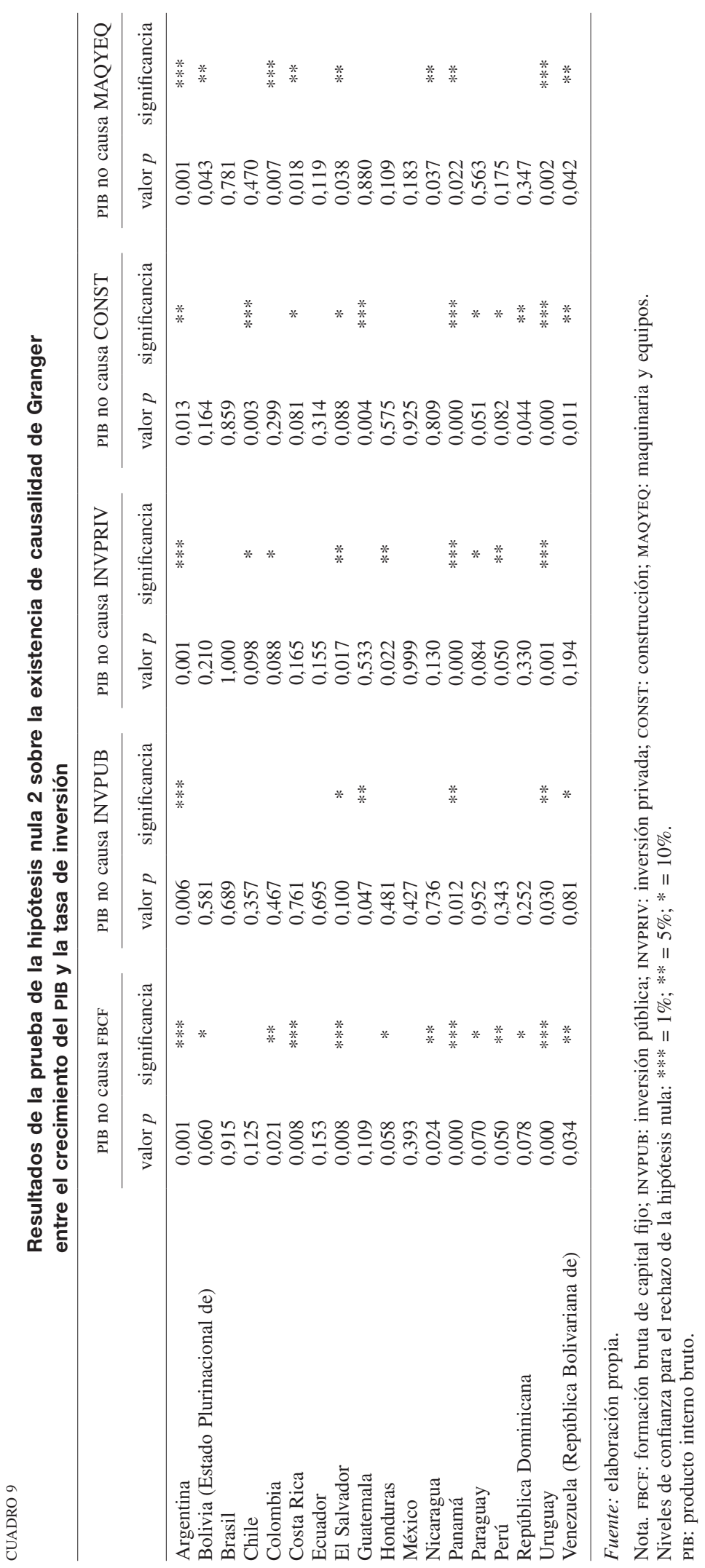


Los resultados generales sugieren que en el período 1980-2010 los aumentos en la tasa de inversión han estado relacionados con estímulos provenientes de la demanda agregada (expectativas de crecimiento o aumento efectivo de la demanda). La evolución de la demanda agregada regional, así como de aquellos factores que la han impulsado, ofrece ciertas pistas para explicar este desempeño. En lo relacionado con la demanda externa, los incrementos han ocurrido sobre todo a través de la mayor demanda mundial de productos básicos y productos energéticos, lo que habría desencadenado un alza en la inversión en esas áreas ${ }^{18}$. A su vez, el aumento en la demanda interna se ha sustentado en buena medida en el dinamismo sostenido del consumo de los hogares, en respuesta a los mejores indicadores de los mercados laborales (disminución del desempleo, aumento del empleo e incremento de los salarios reales) y a la expansión del crédito bancario a las familias. Otro elemento relevante que explica el elevado dinamismo del consumo de los hogares ha sido la aminoración de la pobreza. Este no es un elemento menor, dado que es muy elevada la propensión a consumir de aquellos segmentos de la población de menores ingresos que logran más acceso al consumo de bienes y servicios (generalmente, igual o cercana a 1), por lo que el aumento del ingreso de estas familias se traduce casi en su totalidad en mayor consumo $^{19}$. Un elemento importante que permite arrojar

18 Si bien en la gran mayoría de los países no existen estadísticas sobre la formación bruta de capital fijo (FBCF) por sector de actividad de destino de esta inversión, la información parcial y de otras fuentes sugiere que en los países productores y exportadores de materias primas, la mayor parte se ha destinado a proyectos vinculados con la minería y el sector energético. En el caso de la IED, de 2007 a 2012 en América del Sur (excluido el Brasil), entre el $44 \%$ y el $51 \%$ se orientó al sector de recursos naturales y cerca del $40 \%$ a los servicios, incluidos el comercio y los servicios financieros y de infraestructura. En contraste, en México y Centroamérica, entre el 35\% y el $48 \%$ se destinó al sector manufacturero, y a los servicios entre el 42 y el 55\%. A su vez en el Brasil, entre un $38 \%$ y un $43 \%$ se orientó a manufacturas y entre un $34 \%$ y un $48 \%$ a servicios (CEPAL, 2013b, gráf. I.11).

${ }^{19}$ La relación del aumento del consumo y el nivel del coeficiente de inversión se refleja en la elevada correlación de ambas variables. En Jiménez y Manuelito (2013, anexo 2) se presentan los resultados obtenidos al estimar los coeficientes de correlación de la tasa de luces sobre el mayor consumo en la región es el hecho de que de 2002 a 2011 la tasa de pobreza en América Latina disminuyó de un $43,9 \%$ a un $29,4 \%$ de la población. Si bien la pobreza en la región continúa siendo elevada y su reducción es uno de los desafíos más importantes, este cambio logrado en 10 años representa una merma muy significativa (CEPAL, 2013c). El incremento en la base de consumo resultante de este conjunto de factores ha sido clave en sostener el dinamismo de la inversión en el sector del comercio que se ha verificado en varias de las economías de América Latina.

Con todo, un segundo grupo conformado por la Argentina, el Brasil, Nicaragua y la República Bolivariana de Venezuela muestra una mayor probabilidad de que sean los cambios en la inversión los que causen el crecimiento. Ello podría ser un indicio de que en estos países, durante el período bajo estudio, las restricciones al crecimiento hayan provenido más bien del bajo crecimiento de la capacidad productiva resultante de largos períodos de baja inversión, que de una demanda agregada insuficiente.

La pertenencia de un país a uno u otro grupo es un dato de primera importancia para el diseño de una política macroeconómica orientada al crecimiento y su sostenibilidad. En efecto, en países en los que es más probable que el crecimiento del PIB preceda a la tasa de inversión, mayor relevancia tendrán las políticas de demanda y de carácter contracíclico orientadas a mantener elevado el grado de utilización de la capacidad, a menos que otras restricciones al crecimiento, tales como la disponibilidad de financiamiento externo, conduzcan a una recomendación diferente. A su vez, en los casos en que la tasa de inversión precede a los cambios en el crecimiento del PIB, las políticas orientadas al estímulo de la ampliación de la capacidad productiva cobrarán mayor relevancia. En los casos intermedios, el énfasis variará según cuál sea en cada momento el aspecto más restrictivo del crecimiento, es decir, el nivel de demanda o la capacidad productiva.

variación del consumo total y el coeficiente de inversión total para los 19 países considerados en este estudio. 


\section{IV}

\section{Síntesis y conclusiones}

Sobre la base de estimaciones previamente no disponibles acerca de la inversión y sus componentes en América Latina, en este artículo se pasa revista a sus principales hechos estilizados en el período 1980-2010 y se exploran factores causales en la relación del crecimiento económico y la formación bruta de capital fijo (FBCF).

En el análisis de los datos, se destaca el bajo nivel de inversión en América Latina en comparación con lo observado en otras regiones y, en particular, con países que han reducido en forma significativa la brecha —en términos de su PIB per cápita- que los separa de países desarrollados. Se constatan tres hechos estilizados sobre la inversión en América Latina:

i) el coeficiente de inversión se mantuvo en forma prolongada en niveles inferiores al $20 \%$ en 8 de los 19 países analizados;

ii) comparada con la de los años ochenta, la inversión pública, como porcentaje del PIB, disminuyó en 15 de los 19 países durante el período 1990-1998. Si bien se aprecia una recuperación a partir de 2003 en algunos de ellos, en 12 de los 19 países el coeficiente de inversión pública no ha recuperado el nivel de los años ochenta;

iii) durante los años noventa, la inversión privada tuvo el mayor dinamismo del período 1980-2010 y el coeficiente de inversión aumentó en 14 de los 19 países. A partir de 2003 su desempeño fue dispar. El coeficiente de inversión privada cayó en el subperíodo 2003-2010 en 8 países respecto de los registros de 1999-2002, mientras que en 7 de ellos alcanzó los mayores niveles del período 1980-2010. Esto último, en conjunto con cierta recuperación de la inversión pública en el subperíodo 2003-2010, condujo a que se alcanzaran en estos años los mayores niveles de inversión total.

Entre los principales factores que incidieron en el aumento de los coeficientes de inversión en el subperíodo 1990-1998, se señaló la menor influencia de la restricción externa. Este fenómeno es atribuible a la mayor disponibilidad de divisas debido al proceso de apertura económica y al aumento del poder de compra de las exportaciones generado por la mejoría en los precios de estas, así como a la fuerte reducción de los precios internacionales de los bienes de capital. Pese a ello, el ahorro nacional continuó siendo insuficiente para cubrir la inversión, por lo que el ahorro externo se mantuvo como una fuente importante de financiamiento. Pero en contraste con la década de 1980, los componentes del ahorro externo cambiaron significativamente a partir de los años noventa, adquiriendo la IED un peso creciente ${ }^{20}$.

En el subperíodo 2003-2010, el coeficiente de inversión volvió a repuntar. Uno de los elementos que contribuyó a este dinamismo de la inversión fue, al igual que en el subperíodo 1990-1998, la menor incidencia de la restricción externa como factor limitante del financiamiento. Incluso algunos países y la región en conjunto tuvieron un ahorro externo negativo durante varios años consecutivos. Esto se debió al efecto combinado del incremento del ingreso nacional disponible, ocasionado por la mejoría en los términos de intercambio y la modificación del marco de políticas macroeconómicas, lo que redundó en un significativo aumento del ahorro nacional. Su contrapartida fue la reducción del endeudamiento externo y la acumulación de reservas internacionales y de ahorros en fondos soberanos. El comportamiento del ahorro nacional de 2003 a 2010 marca la principal diferencia respecto del subperíodo 1990-1998. En ambos subperíodos se registró un incremento del coeficiente de inversión, pero el aumento del ahorro nacional durante el segundo subperíodo, junto con la persistencia de la mayor participación en el ahorro externo de flujos financieros externos menos volátiles — que había comenzado en los años ochenta-, determinaron una menor vulnerabilidad externa y mayores espacios para ejercer políticas contracíclicas cuando sobrevino la reciente crisis financiera global.

Con respecto al análisis empírico de la relación entre el crecimiento y la inversión, los resultados obtenidos señalan que, en general, cambios en la tasa de variación del PIB preceden a cambios en el coeficiente de inversión. Resultados análogos se obtienen al analizar la relación de la tasa de variación del PIB con los coeficientes de inversión privada y de inversión en maquinaria y equipo. En un número menor de casos, si bien relevantes por su tamaño relativo en la región, se obtiene que la causalidad, en el sentido de Granger (1969), va desde el cambio en la inversión hacia el crecimiento. La relevancia de estos resultados radica en que ellos contribuyen a identificar en cada caso los factores que limitan el crecimiento y a diseñar una política macroeconómica orientada a estimularlo, tomando en cuenta esas restricciones.

\footnotetext{
${ }^{20}$ Al respecto, véase CEPAL (2013a, cap. I ).
} 


\section{Bibliografía}

Blomström, Magnus, Robert Lipsey y Mario Zehjan (1993), "Is fixed investment the key to economic growth?", NBER Working Paper, $\mathrm{N}^{\circ}$ 4436, Cambridge, Massachusetts, National Bureau of Economic Research (NBER).

Bukhari, Adnan, Liaqat Ali y Mahpara Saddaqat (2007), "Public investment and economic growth in the three little dragons", International Journal of Business and Information, vol. $2, \mathrm{~N}^{\mathrm{o}} 1$.

CEPAL (Comisión Económica para América Latina y el Caribe) (2013a), Estudio Económico de América Latina y el Caribe, 2013 (LC/G.2574-P), Santiago de Chile. Publicación de las Naciones Unidas, $\mathrm{N}^{\circ}$ de venta: S.13.II.G.3.

(2013b), La Inversión Extranjera Directa en América Latina y el Caribe 2012 (LC/G.2571-P), Santiago de Chile. Publicación de las Naciones Unidas, $\mathrm{N}^{\circ}$ de venta: S.13.II.G.4. (2013c), Panorama Social de América Latina, 2012 (LC/G.2557-P), Santiago de Chile. Publicación de las Naciones Unidas, $\mathrm{N}^{\circ}$ de venta: S.13.II.G.6.

(2012), Anuario Estadístico de América Latina y el Caribe, 2012 (LC/G.2554-P), Santiago de Chile. Publicación de las Naciones Unidas, $\mathrm{N}^{\circ}$ de venta: E/S.13.II.G.1.

(2011), Estudio Económico de América Latina y el Caribe 2010-2011 (LC/G.2506-P), Santiago de Chile. Publicación de las Naciones Unidas, $\mathrm{N}^{\circ}$ de venta: S.11.II.G.3.

(2009), "América Latina y el Caribe: Series históricas de estadísticas económicas 1950-2008”, Cuadernos Estadísticos de la CEPAL, No 37 (LC/G.2415-P), Santiago de Chile. Publicación de las Naciones Unidas, $\mathrm{N}^{\circ}$ de venta: S.09.II.G.72.

Cheung, Yin-Wong, Michael Dooley y Vladyslav Sushko (2012), "Investment and growth in rich and poor countries", NBER Working Paper, $\mathrm{N}^{\circ} 17788$, Cambridge, Massachusetts, National Bureau of Economic Research.
Cullison, W.E. (1993), "Public investment and economic growth", Federal Reserve Bank of Richmond Economic Quarterly, vol. 79, $\mathrm{N}^{\circ}$ 4, Richmond, Banco de la Reserva Federal de Richmond.

Granger, C.W.J. (1969), "Investigating causal relations by econometric models and cross-spectral methods", Econometrica, vol. 37, $\mathrm{N}^{\mathrm{o}}$ 3, Econometric Society.

Jiménez, Luis Felipe y Sandra Manuelito (2013), "Rasgos estilizados de la relación entre inversión y crecimiento en América Latina y el Caribe: 1980-2012", serie Macroeconomía del Desarrollo, $\mathrm{N}^{\circ} 136$ (LC/L.3704), Santiago de Chile, Comisión Económica para América Latina y el Caribe (CEPAL).

Manuelito, Sandra y Luis Felipe Jiménez (2013), "La inversión y el ahorro en América Latina: nuevos rasgos estilizados, requerimientos para el crecimiento y elementos para una estrategia para fortalecer su financiamiento", serie Macroeconomía del Desarrollo, № 129 (LC/L.3603), Santiago de Chile, Comisión Económica para América Latina y el Caribe (CEPAL).

Peltonen, Thomas, Ricardo Sousa e Isabel Vansteenkiste (2012), "Investment in emerging market economies", Empirical Economics, vol. 43, No. 1, Springer.

Sala-i-Martin, Xavier (1997), "I just ran two millions regressions", American Economic Review, vol. 87, № 2, Nashville, Tennessee, American Economic Association.

Toulaboe, Dosse, Rory Terry y Thomas Johansen (2009), "Foreign direct investment and economic growth in developing countries", Southwestern Economic Review, vol. 36, No 1, Southwestern Economic Society. 